\title{
The Effect of Aerosols to Climate Change and Society
}

\author{
Bowen Zhang \\ Institute for Marine and Antarctic Studies, University of Tasmania, Hobart, Australia \\ Email: bzhang17@utas.edu.au
}

How to cite this paper: Zhang, B. W (2020). The Effect of Aerosols to Climate Change and Society. Journal of Geoscience and Environment Protection, 8, 55-78. https://doi.org/10.4236/gep.2020.88006

Received: April 27, 2020

Accepted: August 24, 2020

Published: August 27, 2020

Copyright $\odot 2020$ by author(s) and Scientific Research Publishing Inc. This work is licensed under the Creative Commons Attribution International License (CC BY 4.0).

http://creativecommons.org/licenses/by/4.0/

\begin{abstract}
Air pollution and global warming are two of the greatest threats to human and animal health and political stability. The primary global warming pollutants are, in order, carbon dioxide gas, fossil-fuel plus biofuel soot particles, methane gas, 4, 6 - 10 halocarbons, tropospheric ozone, and nitrous oxide gas. About half of actual global warming to date is being masked by cooling aerosol particles. Increased concentrations of ozone and fine particulate matter (PM2.5) since preindustrial times reflect increased emissions, but also contributions of past climate change. Recent analyses have shown that reducing black carbon (BC) emissions, using known control measures, would reduce global warming and delay the time when anthropogenic effects on global temperature would exceed $2^{\circ} \mathrm{C}$. Likewise, cost-effective control measures on ammonia, an important agricultural precursor gas for secondary inorganic aerosols (SIA), would reduce regional eutrophication and PM concentrations in large areas of Europe, China, and the USA. Thus, there is much that could be done to reduce the effects of atmospheric PM on the climate and the health of the environment and the human population.
\end{abstract}

\section{Keywords}

Aerosols, Air Pollution, Climate Change, Effects

\section{Global Warming Introduction with Atmospheric Chemistry and Physics}

\subsection{Climate Change Introduction}

Air, water, and land are associated with the atmosphere by exchanging gases, which is important for the weather and property of climate. The climate has undergone considerable changes due to natural processes in recent decades. However, the last five to ten decades have witnessed the obvious warming of Earth 
(Shove, 2010). Intergovernmental Panel on Climate Change (IPCC) found that the warming of the climate system was undoubtedly and observed changes have never occurred for decades or even thousands of years since the 1950s. Global warming has been extremely apparent and the average global temperature has been increasing since the Industrial Revolution. The year from 1880 to 2000 saw a gradual increase in the mean temperature, and the average temperature rose for around 0.6 degrees Celsius in 2000 (Figure 1) (n.d.). Global warming is a continuous process and the mean temperature is predicted to rise another 0.3 to 0.7 degrees Celsius by 2035.

Human activities, especially the burning of fossil fuels, are related to the generation of greenhouse gases which mainly contain carbon dioxide (Santer et al., 1996). Human activities have caused the increase the radiative forcing which led to the atmospheric carbon dioxide arisen for around 30\%. The research (Liu \& Rodríguez, 2005) for the double concentration of carbon dioxide found that the average global temperature would increase between 2.15 to 3.4 degrees Celsius. In the early twenty century, few studies suggested that temperatures in polar religions had been rising, but these changes have not been formally put down to human activities because of the scarcity of observations and spontaneous change (Polyakov et al., 2003). However, through analyzing the data for the temperatures of the land surface (Gillett et al., 2008), anthropogenic influences are obvious in the poles and the effects of human activity are detectable in the Arctic.

\subsection{Atmospheric Radiation and Photochemistry}

Atmospheric radiation is mostly absorbed by atmospheric gases which include oxygen, water vapor, carbon dioxide, ozone, nitrous oxide, carbon monoxide, and methane (Goody \& Yung, 1995). Carbon dioxide, water vapor, and methane are major greenhouse gases that block the energy from the sun reflecting out to space. Atmospheric photochemistry focus on the interaction between greenhouse gases and incident solar radiation. Greenhouse gases absorb solar radiation

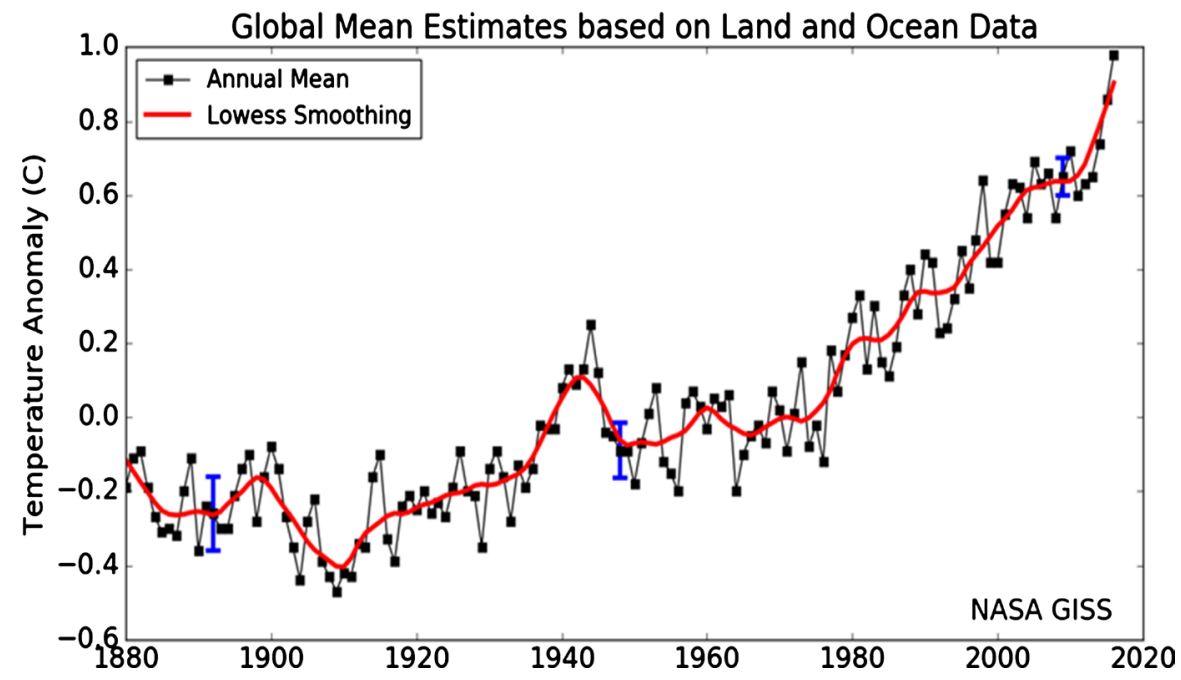

Figure 1. The change of global mean temperature from 1880 to 2020. 
for the atmosphere and then the atmospheric species would be photoionized (Levine, 2012). Earth's climate is warming due to anthropogenic emissions of greenhouse gases, especially carbon dioxide from burning fossil fuel (Montzka, Dlugokencky, \& Butler, 2011).

Anthropogenic emissions also generate aerosols. For instance, the concentration of atmospheric aerosols especially sulfur dioxide is increasing due to industrial activities (Taylor \& Penner, 1994). As opposed to the greenhouse gases, the effect of aerosols is to cool the atmosphere. The sulfate and some organic aerosol particles will scatter solar radiation back into space to cool the Earth's surface, but they also alter the actinic flux of ultraviolet radiation (Dickerson et al., 1997).

The aerosol optical depth and the photolysis rate coefficient are measured by NASA Goddard Space Flight Center. The optical depth and the nature of the aerosol column could be observed from the fourth to the sixth wavelength of solar radiation (Ehara, Hagwood, \& Coakley, 1996). The aerosol optical depth gives information about how much direct sunlight is blocked by aerosols and fails to reach the ground. Photochemical smog or ground-level ozone, has been the most severe air pollution problem, thus, by reducing sulfur and hydrocarbon emissions (Dickerson et al., 1997) may have benefited the air quality.

\subsection{Atmospheric Aerosols}

Atmospheric aerosols are suspensions of submicroscopic and microscopic particles which originate from a variety of natural and anthropogenic sources. Aerosol particles are emitted directly from various sources in the form of liquids or solids, such as biomass burning, incomplete combustion of fossil fuels, volcanic eruption, wind-driven, or traffic-related roads (Pöschl, 2005). The most obvious example of an aerosol in the atmosphere are clouds, which is mainly composed of concentrated water with a particle diameter of about $0.01 \mathrm{~mm}$ (Pruppacher \& Klett, 2010). However, in atmospheric science, the term aerosol has traditionally referred to suspended particles containing a large amount of condensed matter other than water.

Atmospheric aerosols play an important role in climate and atmospheric chemistry. Aerosols affect the climate because they affect the radiation balance of the planet. This can happen directly when particles scatter or absorb sunlight, or indirectly when particles provide atomic nuclei to help form cloud droplets and ice particles, thereby changing the reflectivity and lifetime of the cloud (Andreae \& Crutzen, 1997). Both direct and indirect aerosol effects act toward reducing Sea Surface Roughness (SSR) with increasing aerosol levels. The magnitude of these effects depends on the composition of the individual particles and how they are assembled in the population.

\subsection{Aerosols and Greenhouse Gases}

The effects of greenhouse gases and aerosols are opposite to the climate system. Greenhouse gases which primarily include water vapor $\left(\mathrm{H}_{2} \mathrm{O}\right)$, carbon dioxide 
$\left(\mathrm{CO}_{2}\right)$, methane $\left(\mathrm{CH}_{4}\right)$, nitrous oxide $\left(\mathrm{N}_{2} \mathrm{O}\right)$, and ozone $\left(\mathrm{O}_{3}\right)$ warm the planet's surface by absorbing infrared radiation and preventing it from escaping from the planet (Ehhalt et al., 2001). Combined with the increasing concentration of greenhouse gases in recent years, the greenhouse effect is going to have more impacts not only global warming. Aerosols affect the climate in two primary ways: by changing the amount of heat entering or leaving the atmosphere, or by affecting how clouds are formed. The effect of atmospheric aerosols is more complicated than greenhouse gases (Mitchell et al., 1995), which means that different aerosols reflecting sunlight to varying degrees depending on their physical properties. Generally, bright or translucent particles tend to reflect radiation in all directions and return to space, while dark aerosols could absorb a large amount of light (Watson et al., 1990). Most aerosols are brighter than land or ocean, cooling the earth by reflecting sunlight into space like pure sulfates and nitrates reflect almost all the radiation they encounter, cooling the atmosphere. However, there are some aerosols absorb sunlight such as black carbon which absorbs radiation and warms the atmosphere.

The Earth's radiative balance is affected by the absorption, scattering, and cloud condensation nodule formation characteristics of atmospheric aerosols. However, there still has considerable uncertainty in aerosol radiative forces, partly because of the unknown source of atmospheric aerosols (Yamamoto \& Tanaka, 1969). If the aerosol forcing has a small uncertainty range, the aerosol can only offset a small part of the greenhouse effect. However, if the aerosol forcing is at the high end of the uncertain range, the aerosol may offset almost all current greenhouse gas forcing (Schwartz \& Andreae, 1996). If we assume that aerosols offset most of the greenhouse effect, a possibility that is entirely consistent with current uncertainty. Then the temperature would increase around 0.5 K globally and annually (Houghton, 1996) during the industrial period. If temperature sensitivity is high, global warming may accelerate sharply in the future.

\section{Aerosol Science and Interaction}

\subsection{Properties of Atmospheric Aerosols}

\subsubsection{Aerosol Properties}

Whether in cities or remote areas, the atmosphere contains a large number of aerosol particles. A complete description of the aerosol size distribution may also include calculations for each particle size. Because the position of aerosols varies with time and space, it is difficult to calculate particle size. Besides, changes in atmospheric aerosol concentrations over short time scales are also often quite significant. The size distribution of a particle swarm can also be described by its cumulative distribution (Torres et al., 1998). The cumulative distribution value of the particle size segment is defined as the particle concentration that is less than or equal to the particle size range. What's more, the vertical distribution of aerosol mass concentration generally decreases exponentially with increasing altitude, and the distribution of aerosol mass concentrations above altitude is quite 
stable. As for the chemical composition, atmospheric aerosol particles contain sulfates, nitrates, ammonium, organic matter, crustal matter, sea salt, metal oxides, hydrogen ions, and water. Different experts describe particles based on their shape, size, and chemical composition. Toxicologists call aerosols superfine, fine, or coarse. Fine particles that are less than $2.5 \mu \mathrm{m}$ in diameter are mainly composed of organic aerosol, ammonium nitrate, and sulfate (Mitchell et al., 1995). Coarse particles are relatively large particles_-greater than $2.5 \mu \mathrm{m}$ in diameter such as dust, pollen, spores, and fly ash and are mainly produced by mechanical crushing of larger solid particles.

\subsubsection{Aerosol Classification}

Submicron aerosols are dominated by organic components and nitrates, as well as sulfate, ammonium, and black carbon. The contribution of carbon, nitrogen, and sulfur to the composition illustrates the role of aerosols in the biogeochemical cycle. Compounds that exist as organic aerosols in the atmosphere are a mixture of aerosols and gaseous organics. Organic aerosols are ubiquitous in the atmosphere and account for $20 \%$ to $90 \%$ (Ng et al., 2010) of the total submicron aerosol mass. It is difficult to accurately model them due to the complexity of their sources, composition, and atmospheric aging mechanisms. Organic aerosols are generally divided into primary organic aerosols and secondary organic aerosols (Crippa et al., 2013). Due to the different formation, primary aerosols contain particles introduced directly into the gas and secondary aerosols form through gas-to-particle conversion. With the development of instrument technology, measuring the size distribution of aerosols has enabled scientists to understand the formation of secondary aerosol particles (Turpin \& Huntzicker, 1995). Secondary organic aerosols are formed by the oxidation of volatile organic compounds in the troposphere, and their low vapor pressure oxidation products are distributed between the gas and the aerosol phase.

\subsubsection{Primary Aerosols}

Primary organic aerosols are atmospheric particles that are emitted or injected directly into the atmosphere. These are many kinds of atmospheric primary aerosols (Hodzic et al., 2010), such as smoke, dust, and sea salt. Sand dust aerosols have not only natural sources, but also man-made sources, including urban fugitive dust, which is made of mineral aerosols generated by industrial activities such as incompletely burnt coal dust, road excavation, uncovered, construction sites and cement, and artificial dust produced by human activities such as agricultural activities (Gillett et al., 2008). As one of the main components of aerosol, sand and dust aerosols can not only reflect solar radiation but also act as condensation tuberculosis of the cloud to affect the cloud droplet number concentration and effective radius, thereby changing the cloud's optical thickness and lifetime. The absorption characteristics (Ginoux et al., 2001) of sand dust particles will also affect the heating structure of atmospheric radiation. Sand dust aerosols will not only change the regional atmospheric radiation characteristics 
but also have a great impact on the regional water cycle, monsoon system, and local climate environment (Zhang et al., 2005). Comparing the distribution of sand and dust in different seasons, the distribution of sand and dust has obvious seasonal differences. From the global regional average, spring is the largest, summer is the second, then autumn and winter are the smallest. Aerosol optical thickness (AOD), single-scatter albedo (SSA), asymmetry factor (ASY), and volume spectral distribution are the key parameters to estimate its radiative forcing. At present, there is still a lot of uncertainty in the assessment of the climate and environmental impacts of sand and dust aerosols. The main reason is the lack of understanding of the sand and dust source area (Zhang et al., 2008), the sand and dust transmission process, and the feedback mechanism of the climate system. Besides, there is a lack of system information on the physical, chemical, and optical properties of sand and dust aerosols.

\subsubsection{Secondary Aerosols}

The photooxidation of isoprene results in the formation of secondary organic aerosols. A series of controlled experiments (Surratt et al., 2006) showed that oligomerization is an important way to form secondary organic aerosols. However, the characters of oligomers depend largely on the level of nitrogen oxides, and acidic products are formed only under conditions of high nitrogen oxides. Secondary organic aerosols account for more than $50 \%$ of the total organic mass, including a high oxidation factor from uncertain and different sources and a low oxidation factor related to wood combustion emissions (Crippa et al., 2013). Secondary organic aerosols are formed in the air through physical and chemical processes such as oxidation and then nucleate or condense. Submicron inorganic aerosols are mainly composed of ammonium nitrate and sulfate (Seinfeld, Pandis, \& Noone, 1998), while sub-organic aerosols may be composed of thousands of compounds, many of which are unknown, and there is further uncertainty in the formation path of sub-organic aerosols (Hallquist et al., 2009). Volatile and semi-volatile organic compounds in the atmosphere are oxidized in the atmosphere to form secondary organic aerosols, which are concentrated and enter the atmospheric aerosols and become their constituents. Most secondary organic aerosols exist in the troposphere (Torres et al., 1998) and participate in the formation of clouds, fog, and haze. Besides, they have a serious impact on climate change and air pollution.

\subsection{Dynamics of Single Aerosols Particle}

\subsubsection{The Mean Free Path}

When observing the motion of aerosols in a fluid, we need to start from the perspective of the transport process. For the microscopic scale, a fluid molecule collides with another molecule after moving in a straight line. The molecule changes direction after the collision and collides with another molecule after moving for a while (Jennings, 1988). The average distance a molecule collides with other molecules is defined as the mean free path (Negele \& Yazaki, 1981). 
The mean free path $\lambda$ can be expressed as the length of the path divided by the number of collisions from the Equation (1) $\left(\bar{v}, d\right.$ and $n_{v}$ represent the average velocity, diameter, and number of molecules per unit separately).

$$
\lambda=\frac{\bar{v} t}{\pi d^{2} \bar{v} t n_{v}}=\frac{1}{\pi d^{2} n_{v}}
$$

We can distinguish two cases based on the relative size of the particles suspended in the gas and the average free path of the surrounding gas molecules (Signorell et al., 2016). If the diameter of the particles is much bigger than the mean free path of the surrounding gas molecules, the gas is considered a continuous fluid, thus, the mean free path could be expressed by the above formula. But if the diameter of the particle is much smaller than the mean free path of the surrounding gas, the particle can be unified into another gas molecule because it is small enough (Pruppacher \& Klett, 2010). In this case, the velocity of target molecules should not be ignored and the frequency of the collision depends on the average velocity of the randomly moving molecules. Equation (2) shows the average relative velocity which is needed to calculate the mean free path $\lambda$

$$
\bar{v}_{r}=\sqrt{2} \bar{v}
$$

The result of the mean free path is

$$
\lambda=\frac{1}{\sqrt{2} \pi d^{2} n_{v}}
$$

\subsubsection{Stoke's Law}

According to Avogadro's constant number and ideal gas law (Deslattes et al., 1974), the number of molecules per unit volume can be determined

$$
n_{v}=\frac{n N_{A}}{v}=\frac{n N_{A}}{\frac{n R T}{P}}=\frac{N_{A} P}{R T}
$$

Thus, the mean free path could be expressed as:

$$
\lambda=\frac{R T}{\sqrt{2} \pi d^{2} N_{A} P}
$$

As long as the aerosol particles do not move in a vacuum which is not ideal, resistance will always exist. To calculate the resistance of a fluid to a particle moving in the fluid, you need to solve the fluid motion equation (Arnold, 1911) to determine the velocity and pressure fields around the particle. In incompressible Newtonian fluids (Jalaal \& Ganji, 2011), the relationship between velocity and pressure is determined by a continuous equation:

$$
\frac{\partial u_{x}}{\partial x}+\frac{\partial u_{y}}{\partial y}+\frac{\partial u_{z}}{\partial z}=0
$$

And the Navier-Stokes equation, where the $\mathrm{x}$ component is (where $g_{\mathrm{x}}$ is the component of gravity in the $\mathrm{x}$-direction): 


$$
\rho\left(\frac{\partial u_{x}}{\partial t}+u_{x} \frac{\partial u_{x}}{\partial x}+u_{y} \frac{\partial u_{y}}{\partial y}+u_{z} \frac{\partial u_{z}}{\partial z}\right)=-\frac{\partial \rho}{\partial x}+\mu\left(\frac{\partial^{2} u_{x}}{\partial x^{2}}+\frac{\partial^{2} u_{x}}{\partial y^{2}}+\frac{\partial^{2} u_{x}}{\partial z^{2}}\right)+\rho g_{x}
$$

By introducing characteristic velocity Uo and length $L$, the continuity equation and Navier-Stokes equation can be made dimensionless. Reynolds number $R e=u_{0} L \rho / u$, which is the ratio of inertial force to viscous force inflow, is a characteristic dimensionless group that appears in a dimensionless equation (Collins \& Keswani, 2004). For the flow around the submerged body, $L$ can be selected as the characteristic size of the body, such as diameter, and $u_{0}$ can be selected as the velocity of the undisturbed fluid upstream of the body. When the particle size is small and the flow velocity is low, the Reynolds number is small and the flow is laminar (Sehmel, 1968). In this case, the inertial force is negligible compared to the viscous force. Newton's law is no longer valid, and Stokes' law should be used, in the form:

$$
F_{D}=3 \pi \eta V d_{p}
$$

To determine the drag coefficient in the Stokes equation, we can compare the above equation with Newton's drag equation (Howells, 1974):

$$
F_{D}=C_{D} \frac{\pi}{8} \rho_{g} d_{p}^{2} V^{2}
$$

Then we can get the drag coefficient in the laminar flow regime. Inversely proportional to the drag coefficient $R e_{p}$ :

$$
C_{D}=\frac{24 \eta}{\rho_{g} d_{p} V}=\frac{24}{R e_{p}}
$$

\subsubsection{In the External Force Field and Reynolds Number}

The movement of aerosol particles is first caused by certain external forces, such as gravity or electricity (Alonso, 2002). When the speed of the particles differs from the speed of the fluid, resistance is created. To describe the motion of particles when they are subjected to external forces in a stationary or flowing fluid, the particle's equation of motion is the basis (where $v$ is the particle velocity and $F_{i}$ is the force $\mathrm{i}$ acting on particles).

$$
m_{P} \frac{\mathrm{d} v}{\mathrm{~d} t}=\sum_{i} F_{i}
$$

The acceleration experienced by a particle is proportional to the sum of the forces acting on the particle. The above equations are used for "deterministic" forces, namely gravity, drag, and electricity (Alonso, 2002). The combined force exerted by the fluid on the sphere in the direction of flow is composed of two parts. At each point on the surface of the sphere, there is a pressure on the solid perpendicular to the surface of the sphere. This is a normal force. At each point, the fluid also exerts a tangential force due to the shear stress caused by the velocity gradient near the surface. To obtain the reaction force on the spherical surface, it is necessary to integrate the pressure component perpendicular to the spherical surface (Ehara, Hagwood, \& Coakley, 1996). The normal and tangen- 
tial forces are ( $u_{\infty}$ is the undisturbed fluid velocity upstream of the far sphere):

$$
\begin{gathered}
F_{n}=2 \pi u R_{P} u_{\infty} \\
F_{t}=4 \pi u R_{P} u_{\infty}
\end{gathered}
$$

A sphere moving at velocity $u$ in a fluid is perfectly equivalent to a sphere moving at velocity $\mathrm{u}$ in a stationary fluid. The total resistance of the fluid to the sphere is:

$$
F_{\text {drag }}=F_{n}+F_{t}=6 \pi u R_{P} u_{\infty}
$$

If we include gravity, the total force acting on the sphere is the sum of drag and buoyancy. When the direction of flow coincides with the direction of gravity, the buoyancy added to the resistance is equal to the weight of the fluid discharged by the sphere

$$
F_{\text {buoyant }}=\frac{4}{3} \pi R_{p}^{3} \rho g
$$

At $R e=1$, the resistance predicted by Stokes' law is reduced by $13 \%$ because the inertia term in the equation of motion is ignored. After correction (Gentry, $1972)$, the proportion is higher, and the Reynolds number is $(R e \leq 2)$

$$
F_{\text {drag }}=6 \pi u R_{P} u_{\infty}\left(1+\frac{3}{16} R e+\frac{9}{160} \operatorname{Re}^{2} \operatorname{In} 2 R e\right)
$$

To consider the resistance in the entire Reynolds number range, we can express the resistance with the empirical resistance coefficient $C_{D}\left(A_{p}\right.$ is the projected area of the body normal to the flow)

$$
F_{\text {drag }}=C_{D} A_{p} \rho \frac{u_{\infty}^{2}}{2}
$$

When the drag coefficient is a function (Choudhury \& Idso, 1985), the following correlations are available in Reynolds numbers:

$$
C_{D}=\left\{\begin{array}{lc}
\frac{24}{R e} & R e<0.1 \text { (Stoke's law) } \\
\frac{24}{R e}\left(1+\frac{3}{16} \operatorname{Re}+\frac{9}{160} \operatorname{Re}^{2} \operatorname{In} 2 R e\right) & 0.1<\operatorname{Re}<2 \\
\frac{24}{R e}\left(1+0.15 \operatorname{Re}^{0.687}\right) & 2<\operatorname{Re}<500 \\
0.44 & 500<\operatorname{Re}<2 \times 10^{5}
\end{array}\right.
$$

\subsubsection{Brownian Motion}

Brownian motion is the random movement of particles suspended in a fluid due to the bombardment of surrounding fluid molecules (Karatzas \& Shreve, 1998). To describe the Brownian motion process, what we need is not considering the interaction between particles and fluid but assuming that the particle motion consists of statistically independent continuous displacements (Durrett \& Durrett, 1984). Brownian motion of a small particle in a stationary fluid is controlled by the following Langevin equation in the $\mathrm{x}$-direction. 


$$
\frac{\mathrm{d} v}{\mathrm{~d} t}+\frac{3 \pi u d}{C_{c} m} u=n(t)
$$

where $\mathrm{v}$ is the particle velocity and $n(t)$ is a white noise due to the effect of fluid molecules on particles. Because of the noncontinuous forces on the suspended fluid molecules, the suspended fluid molecules cause irregular and sharp movements to the particles and the random acceleration $n(t)$ is discontinuous. Due to the existence of $n(t)$, the motion of any particle, that is, the trajectory is a random process (Gupta \& Peters, 1985). To study Brownian motion, the behavior of the entire particle swarm or particle ensemble must first be considered. Suppose that a particle moves in the $y$-direction at $t=0$, the displacement of the particle from the start initial position $(y=0)$ to the position in time $t$ is called $y(t)$. If a large number of particles are released from the origin and all their $y$ displacements at time $t$ are averaged, the expected overall average displacements should be zero (Davies, 1979). This is because there is no constant $n(t)$ inherent in a specific direction. The mean square displacement of the Brownian motion can be expressed as:

$$
\left\langle\chi^{2}\right\rangle=\left\langle y^{2}\right\rangle=\left\langle z^{2}\right\rangle=\frac{2 k T C_{c} t}{3 \pi \mu D_{p}}
$$

Brownian motion is a continuous random process and its essence is the random motion of brown particles under the random impact of molecules. It is impossible that aerosol particles move in a vacuum environment, thus, we need to consider the external resistance to know the motion of the particles. The mean free path is a good reference variable.

\subsection{Thermodynamic of Aerosols}

\subsubsection{Hygroscopicity of Aerosols}

Aerosol hygroscopicity refers to the properties exhibited during the process of water absorption and dehydration of atmospheric aerosols (Tang \& Munkelwitz, 1993). Deliquescence and weathering are the two most important phase transition processes for studying the hygroscopicity of aerosol particles. During the water absorption process, due to the irregular shape of the aerosol particles and the diversity of the internal structure, water vapor in the environment adheres to the aerosol particles through physical adsorption, chemical absorption, and capillary adsorption. For water-soluble chemical components, when the relative humidity of the environment increases to a certain value, atmospheric particles will quickly absorb a large amount of water vapor and become droplets (Cruz \& Pandis, 2000). This relative humidity is called the deliquescent point, which is the saturation concentration point of the droplets. When the relative humidity continues to increase, the droplets can continue to absorb water, which causes the concentration in the droplets to decrease and the volume to increase. It is shown that solid-phase aerosol particles do not absorb water and their volume and mass remain unchanged until the relative humidity doesn't reach the supernode. For chemical components that are insoluble in water, a liquid-water-encapsulated 
core structure may be formed (Zhang et al., 2008). In the process of dehydration, aerosol droplets often do not crystallize into a solid at the deliquescent point. When the ambient relative humidity drops below the deliquescent point, the droplets tend to form metastable supersaturated aerosol droplets. When the relative humidity continues to drop, the droplet concentration gradually reaches the critical concentration of the supersaturated aerosol, and the water content begins to evaporate with solid aerosol particles forming. The deliquescent point of the same compound is often higher than the weathering point (Gysel, Weingartner, \& Baltensperger, 2002), which is called hysteresis causing by homogeneous nucleation or heterogeneous nucleation.

\subsubsection{Aerosols, Clouds and Water Cycle}

As an organic part of the atmospheric hydrosphere cycle, atmospheric aerosols mainly affects the microphysical processes of clouds and precipitation, and also affects atmospheric stability and cloud albedo. Aerosol particles could serve as a kind of cloud condensing nodules and ice nuclei, which play an important role in the formation and growth of cloud rain (Hess, Koepke, \& Schult, 1998). It not only increases or decreases the amount of rainfall, but also changes the type of cloud and rain such as converting non-precipitating clouds into precipitation clouds. This mechanism is called the indirect effect of atmospheric aerosols (Winker, Pelon, \& McCormick, 2003). What's more, through indirect effects, the radiation characteristics, cloud cover, and lifetime of clouds will be changed.

The indirect effects of atmospheric aerosols are closely related to changes in the water cycle in the climate system. The most critical parameter that determines the indirect effects of atmospheric aerosols is the effectiveness of aerosol particles as cloud condensing nodules (Winker, Pelon, \& McCormick, 2003). If the liquid water content does not change, the effect of aerosols on cloud droplet concentration or size caused by microphysical processes is called the first type of indirect effect. Due to the introduction of more aerosol particles as condensed nodules, under a certain water content, cloud droplets compete with each other for water vapor, and they cannot grow up to the precipitation mass point (Ramanathan et al., 2001). Thus, there are more small cloud droplets in the cloud, which results in a decrease in precipitation. Also, due to the enhanced albedo of small cloud droplets (Rosenfeld et al., 2008), a stronger reflection effect is generated, resulting in the ground and the atmosphere becomes colder. Therefore, this indirect effect is also called the "albedo effect of clouds". From the above, we know that once aerosol particles enter the cloud, they could change the precipitation properties and radiation characteristics of the cloud, thereby affecting the precipitation and water cycle.

\subsection{Interactions of Aerosols with Radiation}

\subsubsection{Mechanism of Aerosol with Radiation}

The energy balance of the earth-atmosphere system is the driving force that determines the climate state of the earth. The short-wave solar radiation received at 
the top of the atmosphere by the ground-gas system must be equal to the long-wave or infrared radiation emitted by the ground-gas system itself (Murthy, 1988). For whatever reason, if this balance is disturbed or disrupted, it will cause climate change. In other words, this disturbance either reduce or increase the received solar radiation and the emitted long-wave radiation from the earth, which could lead to the energy budget of the earth-gas system deviates from its equilibrium state. A physical quantity that measures out of equilibrium (Sokolik \& Toon, 1996) is called radiative forcing (RF). If RF is positive, it means that the energy received by the earth's gas system is greater than the energy lost, and then the earth's gas system will be warmer and warmer (Stier et al., 2007). For example, the greenhouse effect caused by the increasing concentration of greenhouse gases reduces the long-wave radiation emitted or lost by the earth-gas system. Since the incident solar radiation is unchanged, RF is positive, and the earth-gas system will warm up (Liao \& Seinfeld, 1998), leading to global warming. Radiative forcing is, therefore, a very useful physical quantity (Murthy, 1988) to characterize how much the Earth's climate system is affected.

\subsubsection{Different Effects of Atmospheric Aerosols and Greenhouse Gases} Atmospheric aerosols and greenhouse gases affect the Earth's climate in the same way, but aerosols are different from greenhouse gases. Greenhouse gases affect long-wave radiation, while aerosols mainly affect solar short-wave radiation (Kiehl \& Briegleb, 1993). Aerosols have a cooling effect on the ground, partially offsetting global warming caused by greenhouse gases. While, due to their physical properties, different types of aerosol particles have different absorption and scattering effects, so that the radiative forcing in the atmosphere is different.

Atmospheric aerosol particles have two climate effects. The first effect is to reduce the solar radiation reaching the ground by scattering and absorbing sunlight then cool the surface of the earth (Taylor \& Penner, 1994), which could offset part of the warming effect caused by greenhouse gases. Secondly, used as condensed nodules in clouds to change cloud microphysical processes and precipitation properties, aerosols could change the water cycle of the atmosphere which also have important impacts on many aspects of economic society (Mitchell et al., 1995), such as agriculture, water resources, human health, and urbanization.

\subsubsection{Aerosols and Global Temperature Change}

For climate change in the past centuries, the general trend is warming, which is mainly caused by human activities and natural changes. The cooling effect of anthropogenic sulfate aerosols in the tropospheric atmosphere on the ground surface could offset some of the warming effects (Solomon et al., 1998) caused by greenhouse gases. However, the spatial-temporal heterogeneity of aerosol distribution on the global scale and the differences in the radiation characteristics of different components have led to great differences in estimates of direct radiative forcing effects (Rood et al., 1985). Therefore, a clean atmosphere in the fu- 
ture can cause global temperatures to increase faster and higher, leading to a more severe global warming situation.

Black carbon aerosols are ranked second to carbon dioxide in contributing to the greenhouse effect. Black carbon aerosol refers to a kind of particulate matter emitted to the atmosphere (Highwood \& Kinnersley, 2006) from the incomplete combustion of fossil and biomass fuels. Black carbon aerosols have a stronger absorption of sunlight so that they can heat the atmosphere. At the same time, due to reflection and absorption in the atmosphere, a part of the incident solar radiation is lost, which also cools the surface. Its main characteristics are high endothermic (Anenberg et al., 2012), light absorption properties, and good thermal stability. The particles are usually not present alone but are present in admixture with other salt particles, especially sulfate particles (Booth \& Bellouin, 2015). The unique characteristics of the particulate matter determine its many complex effects on atmospheric quality, climate, temperature, and human health.

\subsection{Effect of Aerosols}

\subsubsection{Effect on Agriculture}

Impacts of atmospheric aerosols and storm zones on agriculture and ecosystems are mainly caused by the reduction of direct solar radiation reaching the ground (Chameides et al., 1999). Firstly, due to the weakened solar light, photosynthesis of crops is significantly affected, that is, changing the quantity and quality of photosynthetically active radiation. Also, other relevant climatic factors and conditions such as temperature, precipitation, and humidity are affected which finally hinder the growth of crops (Sharma et al., 2010). Secondly, a large amount of sulfur dioxide gas is emitted from the combustion of fossil fuels, causing a gas-particle conversion process to form sulfate aerosols. Sulfate pollutants fall from the atmosphere to the ground surface through two forms (Liousse et al., 1996): wet and dry sedimentation. Wet deposition is mainly manifested by the rinse effect of precipitation on sulfate aerosols (Bréon, Tanré, \& Generoso, 2002), resulting in acid rain. Acid rain has a significant impact on crops and ecosystems, also, it could cause soil acidification. The soil contains a large amount of aluminum hydroxide, after acidification of the soil, the formation of weathering of primary and secondary minerals containing aluminum is accelerated and a large amount of aluminum is released (Du et al., 2014). Long-term and excessive absorption of aluminum ions in plants can poison and even die.

Thirdly, nitrogen aerosols also cause acidification when they settle into the ecosystem. Nitrogen oxides can produce photochemical smog through photochemical reactions, making the plant dwarf, grow thin, and reduce fruit set rate (Lin et al., 2014). Corroded by the fluoride produced by the combustion of coal with high fluorine content in the air, the plants are severely damaged, besides, the forests were gradually reduced and the growth and quality of crops will be significantly damaged. 


\subsubsection{Effect on Human Health}

The composition of atmospheric aerosols is very complex, not only including various gases and particulates produced by natural and human activities, but also containing many types of microorganisms (Callahan-Lyon, 2014), both of which could pose serious threats to human health. There are three different aspects of effects for different sizes of aerosols. The biggest impact on human health is the stable atmospheric aerosol particles with a diameter of 0.1 to $10 \mu \mathrm{m}$ (PM 10) that float in the atmosphere for a long time, which can be directly sucked into the respiratory tract by the human body. Particles with a diameter of 0.1 to $2.5 \mu \mathrm{m}$ (PM 2.5) enter the lungs or into the alveoli directly (Lighty, Veranth, \& Sarofim, 2000). Besides, they can enter the blood to the whole body which is very harmful to human health due to their toxicity. The central lung disease has the most direct relationship with the particulate matter content in the polluted air (Goldsmith, 1986). The second aspect of the health effects for atmospheric aerosols is the effect of heavy metal components in aerosol fine particles could be harmful to human health, which is related to many diseases and harms many parts of the human body. The third aspect of the health effects of atmospheric aerosols is that there are many carcinogens in aerosols' chemical composition (Davidson, Phalen, \& Solomon, 2005), such as polycyclic aromatic hydrocarbons and nitrosamines. The example of nitrosamine aerosols are harmful is that the detection of nitrosamine compounds in mothers' blood during their pregnancy, which shows that mothers who prolonged exposure to tobacco smoke have a high possibility (Myers \& Yeakub Ali, 2008) of miscarriage.

\section{Environmental Policy and Solution}

\subsection{Significance of Aerosol Research}

The particle size of aerosol particles is similar to the wavelength of visible light and has a scattering effect on visible light, which greatly reduces the visibility of the atmosphere and forms air pollution (Uchino \& Tabata, 1991). It also affects many aspects such as transportation and national defense. At the same time, it increases the fuel consumption of lighting electricity and increases air pollution, which forms a vicious circle and negative feedback. On the other hand, aerosol particles can be formed in a wide range of sizes due to the differences in the composition, structure, concentration and aerosol sources (Spendlove \& Fannin, 1983), which could lead to the different effects of light such as absorption, scattering, and refraction. These effects directly or indirectly affect the composition of the atmosphere, temperature changes, precipitation, and sea-level rise which finally affect the stability of the entire ecosystem.

With the rapid development of the global economy in recent years, a large amount of industrial waste gas is emitted into the atmosphere and the environment, which not only affects the climate change of the atmosphere, but also seriously endangers human health and the survival of other animals and plants (Fuchs \& Sutugin, 1971). In recent years, the level of air pollution in large and 
medium-sized urban areas worldwide, especially in developing countries, has increased, affecting many aspects of human health, production, life, and transportation. As the air contains a large number of industrial waste gases that are harmful to our health, these gases can be adsorbed on the aerosol surface or react with the aerosol (Dockery, Schwartz, \& Spengler, 1992). Besides, the deeper and finer particles enter the part of the respiratory tract, the greater the impact would affect the respiratory system. Aerosols become carriers of harmful gases, bringing harmful gases from the air into the human body, which can cause a variety of heart diseases such as asthma, pneumonia, bronchitis, and heart disease. Particles with a size less than $10 \mu \mathrm{m}$ (PM 10) have large inertia and are generally deposited in the nasal mucosa and upper respiratory tract area. Those particles whose sizes are less than $2.5 \mu \mathrm{m}$ (PM 2.5) could be deposited into the bronchi and alveoli through diffusion.

Air pollution is mainly caused by atmospheric aerosols. Atmospheric aerosols can be emitted directly as particulate matter or indirectly formed in the atmosphere by gaseous precursors through chemical reactions such as photochemical reactions (Fan et al., 2004). The main physical process of atmospheric aerosols affecting the climate system is to change the radiation balance of the geogas system by direct scattering and absorption of solar radiation and long-wave radiation. This mechanism is generally defined as the direct action of aerosols (Dickerson et al., 1997). Sulfate aerosols, for example, have a strong effect of reflecting solar radiation, thus increasing the earth's planetary albedo and cooling the atmosphere and surface. The increasing concentration in atmospheric aerosols reduces the quality of the air and the amount of solar radiation reaching the ground. This negative radiative forcing which counteracts the warming in determining surface temperature, precipitation, and evaporation is the opposite of the greenhouse gas effect (Dickerson et al., 1997). Once the aerosols are removed from the atmosphere, the increase in greenhouse gas emissions will be even more dramatic. Therefore, what needs to be considered in the environmental strategy is not only the reduction in $\mathrm{CO}_{2}$ emission, but also the consequences of improving air quality.

\subsection{Climate Change Legislation around the World}

The Paris Agreement came into effect in November 2016, and then more than 190 countries around the world made national contributions to reduce emissions (Rogelj et al., 2016). This is the third landmark international law in human history to deal with climate change. Different from previous international emission reduction cooperation models, The Paris Agreement is a new global climate governance model in which countries around the world independently propose emission reduction targets (Schleussner et al., 2016). The participation of cities in climate governance around the world has become one of the hot spots in the current response to climate change. The climate governance model of The Paris Agreement for the first time affirmed the important role of non-state actors such 
as local government and businesses which is multi-layered governance for climate change (Falkner, 2016). Compared to the governance from a country, cities in the country have more governance flexibility and certain advantages in mobilizing resources and implementing regional strategies. The decentralization trend under globalization has continuously improved the status and roles of cities in environmental governance.

If keep the global average temperature rise within $1.5^{\circ} \mathrm{C}$, cities in Europe, North America, and Australia should reach the peak of carbon emission by 2020 (Dimitrov, 2016), while other cities need to do so by 2030. At present, there are roughly two ways for cities to participate in climate governance (Shove, 2010). The first one is to formulate policies and regulations related to climate change within the city, and propose a path for climate governance under the city's carbon emission mitigation goals. The second one is to promote action on climate change among cities through the global alliance of cities. Globally, a large number of cities are currently actively implementing emission reduction policies to mitigate climate change. For instance, TransformTO is approved by City Council in July 2017 in Toronto. The strategy proposes a series of long-term low-carbon targets (de Vera, 2019), including reducing emissions by 30\% from 1990 levels by 2020 and 65\% from 1990 levels by 2030 (Gu, 2019). Finally achieving net-zero emissions by 2050 to reduce local greenhouse gas emissions and improve residents' health and economic growth. Besides, the California State Senate passed Assembly Bill (AB) in August 2006, which hopes to achieve the goal of reducing emissions by $25 \%$ (Abrego, 2008) through managing oil and gas refineries.

\subsection{Potential Solutions and Suggestions}

Climate change caused by human activities is a major environmental issue in today's society. Among its many influencing factors, the climate effect of aerosols is the most uncertain one (Hiller et al., 1980). It is difficult to accurately understand today's climate change from the perspective of atmospheric dynamics because abnormal climate change is closely related to aerosols. Due to the differences in the distribution of aerosol emission sources and their short residence time in the atmosphere (Kaufman \& Koren, 2006), they will have a greater impact on the regional climate. It is obvious that we should not fold our hands and wait to be slain with regard to certain negative effects of aerosols, but adopt a reasonable method to promote strengths and avoid weaknesses when facing how to deal with these problems. Here, I suggest some specific control aspects and measures that might reduce the effect of aerosols:

i. Strengthen the control in urban industrial areas. The process of urban industrialization is a major reason for the increase in anthropogenic aerosol emissions. Therefore, reasonable observation of emission sources, scientific devices, and effective measures are helpful for emission control. Monitoring in high-emission areas can also promote the government's active performance of administrative duties. 
ii.Establish uniform standards for polluting particles and strengthen monitoring. The feasible method is: on the premise of unifying the particle standard, the division of functions among the departments is provided by the meteorological bureau. For example, the environment division should formulate and manage administrative regulations to prevent the untrueness of the data of the designated meteorological bureaus, cross-spot spot checks could be used for data monitoring.

iii. Treaties and legal mechanisms to strengthen domestic and international cooperation. The international restrictions and enact mandatory compensatory laws should be strengthened to protect the country from the harm caused by unnecessary anthropogenic aerosol emissions.

\section{Conclusion}

From the above analysis, it can be concluded that atmospheric aerosol particles also have climatic effects. Firstly, by scattering and absorbing sunlight, reducing the solar radiation reaching the ground has a cooling effect, which can offset part of the warming effect caused by greenhouse gases. The second is to change the microphysical process of clouds and the nature of precipitation as condensed nodules in the cloud, and change the atmospheric water cycle. Atmospheric aerosols also have important effects on many aspects (Deslattes et al., 1974) of economic society, such as agriculture, water resources, human health, and urbanization. Besides, climate change and air pollution have a common cause to a large extent, that is, they are mainly caused by emissions of fossil fuel combustion. On the one hand, the emitted aerosols not only cause air pollution but also have obvious climatic effects and changes in the hydrosphere cycle. On the other hand, climate change caused by the increase of greenhouse gases (Turco et al., 1980) can also affect air pollution, which can aggravate and amplify the impact of air pollution on human health, agricultural production, and ecosystems. The two are closely related to scientific issues.

Therefore, a unified rather than separate scientific research strategy should be adopted. Especially in the future, with the continuous treatment and improvement of air pollution, their cooling effect will be greatly reduced, which will further increase the reduction of greenhouse gas emissions in the future, otherwise, the global temperature will increase at a faster rate and magnitude (Miller \& Tegen, 1998), which will become an important issue in the next 20 to 30 years. At present, this issue has been solving internationally. And if we do not consider the offset effect of aerosol cooling but only consider how much temperature rise the global greenhouse gas will cause, the global emission reduction responsibility will increase greatly. Therefore, it is necessary and urgent to adopt and formulate collaborative or coupled research and countermeasure strategies. This is an integrated strategy to deal with climate change and air pollution. Solving these problems from the same source is not only more economically effective, but also solves the problems of atmospheric environment and climate change at the same 
time, which can get the greatest economic savings and a win-win effect (Liu et al., 2012). Internationally, it will establish a good image of not only actively protecting the environment but also striving to mitigate climate change.

\section{Acknowledgements}

The author thanks for Jingjing Dai and Erik S. YAN of the University of California, Los Angeles for instructions about aerosol properties.

\section{Conflicts of Interest}

The author declares no conflicts of interest regarding the publication of this paper.

\section{References}

Abrego, L. (2008). Legitimacy, Social Identity, and the Mobilization of Law: The Effects of Assembly Bill 540 on Undocumented Students in California. Law \& Social Inquiry, 33, 709-734. https://doi.org/10.1111/j.1747-4469.2008.00119.x

Alonso, M. (2002). Reducing the Diffusional Spreading Rate of a Brownian Particle by an Appropriate Non-Uniform External Force Field. Journal of Aerosol Science, 33, 439-450. https://doi.org/10.1016/S0021-8502(01)00190-2

Andreae, M. O., \& Crutzen, P. J. (1997). Atmospheric Aerosols: Biogeochemical Sources and Role in Atmospheric Chemistry. Science, 276, 1052-1058.

https://doi.org/10.1126/science.276.5315.1052

Anenberg, S. C., Schwartz, J., Shindell, D., Amann, M., Faluvegi, G., Klimont, Z., JanssensMaenhout, G., Pozzoli, L., Van Dingenen, R., \& Vignati, E. (2012). Global Air Quality and Health Co-Benefits of Mitigating Near-Term Climate Change through Methane and Black Carbon Emission Controls. Environmental Health Perspectives, 120, 831-839. https://doi.org/10.1289/ehp.1104301

Arnold, H. D. (1911). LXXIV. Limitations Imposed by Slip and Inertia Terms Upon Stoke's Law for the Motion of Spheres through Liquids. The London, Edinburgh, and Dublin Philosophical Magazine and Journal of Science, 22, 755-775. https://doi.org/10.1080/14786441108637174

Booth, B., \& Bellouin, N. (2015). Climate Change: Black Carbon and Atmospheric Feedbacks. Nature, 519, 167-168. https://doi.org/10.1038/519167a

Bréon, F.-M., Tanré, D., \& Generoso, S. (2002). Aerosol Effect on Cloud Droplet Size Monitored from Satellite. Science, 295, 834-838.

https://doi.org/10.1126/science.1066434

Callahan-Lyon, P. (2014). Electronic Cigarettes: Human Health Effects. Tobacco Control, 23, ii36-ii40.

Chameides, W. L., Yu, H., Liu, S., Bergin, M., Zhou, X., Mearns, L., Wang, G., Kiang, C., Saylor, R., \& Luo, C. (1999). Case Study of the Effects of Atmospheric Aerosols and Regional Haze on Agriculture: An Opportunity to Enhance Crop Yields in China through Emission Controls? Proceedings of the National Academy of Sciences of the United States of America, 96, 13626-13633. https://doi.org/10.1073/pnas.96.24.13626

Choudhury, B. J., \& Idso, S. B. (1985). An Empirical Model for Stomatal Resistance of Field-Grown Wheat. Agricultural and Forest Meteorology, 36, 65-82.

https://doi.org/10.1016/0168-1923(85)90066-8 
Collins, L. R., \& Keswani, A. (2004). Reynolds Number Scaling of Particle Clustering in Turbulent Aerosols. New Journal of Physics, 6, 119.

https://doi.org/10.1088/1367-2630/6/1/119

Crippa, M., DeCarlo, P., Slowik, J., Mohr, C., Heringa, M., Chirico, R., Poulain, L., Freutel, F., Sciare, J., \& Cozic, J. (2013). Wintertime Aerosol Chemical Composition and Source Apportionment of the Organic Fraction in the Metropolitan Area of Paris. Atmospheric Chemistry and Physics, 13, 961-981.

https://doi.org/10.5194/acp-13-961-2013

Cruz, C. N., \& Pandis, S. N. (2000). Deliquescence and Hygroscopic Growth of Mixed Inorganic-Organic Atmospheric Aerosol. Environmental Science \& Technology, 34, 4313-4319. https://doi.org/10.1021/es9907109

Davidson, C. I., Phalen, R. F., \& Solomon, P. A. (2005). Airborne Particulate Matter and Human Health: A Review. Aerosol Science and Technology, 39, 737-749.

https://doi.org/10.1080/02786820500191348

Davies, C. (1979). Coagulation of Aerosols by Brownian Motion. Journal of Aerosol Science, 10, 151-161. https://doi.org/10.1016/0021-8502(79)90064-8

de Vera, M. K. (2019). Vulnerable Communities and Municipal Climate Change Policy in Toronto. In P. E. Perkins (Eds.), Local Activism for Global Climate Justice: The Great Lakes Watershed (p. 58). London: Routledge. https://doi.org/10.4324/9780429320705-6

Deslattes, R., Henins, A., Bowman, H., Schoonover, R., Carroll, C., Barnes, I., Machlan, L., Moore, L., \& Shields, W. (1974). Determination of the Avogadro Constant. Physical Review Letters, 33, 463. https://doi.org/10.1103/PhysRevLett.33.463

Dickerson, R., Kondragunta, S., Stenchikov, G., Civerolo, K., Doddridge, B., \& Holben, B. (1997). The Impact of Aerosols on Solar Ultraviolet Radiation and Photochemical Smog. Science, 278, 827-830. https://doi.org/10.1126/science.278.5339.827

Dimitrov, R. S. (2016). The Paris Agreement on Climate Change: Behind Closed Doors. Global Environmental Politics, 16, 1-11. https://doi.org/10.1162/GLEP a 00361

Dockery, D. W., Schwartz, J., \& Spengler, J. D. (1992). Air Pollution and Daily Mortality: Associations with Particulates and Acid Aerosols. Environmental Research, 59, 362-373. https://doi.org/10.1016/S0013-9351(05)80042-8

Du, Y.-J., Wei, M.-L., Reddy, K. R., Liu, Z.-P., \& Jin, F. (2014). Effect of Acid Rain pH on Leaching Behavior of Cement Stabilized Lead-Contaminated Soil. Journal of Hazardous Materials, 271, 131-140. https://doi.org/10.1016/j.jhazmat.2014.02.002

Durrett, R., \& Durrett, R. (1984). Brownian Motion and Martingales in Analysis, Wadsworth Advanced Books \& Software California. Environmental and Energy Study Institute. https://www.eesi.org/climate-change-FAQ

Ehara, K., Hagwood, C., \& Coakley, K. J. (1996). Novel Method to Classify Aerosol Particles According to Their Mass-to-Charge Ratio-Aerosol Particle Mass Analyser. Journal of Aerosol Science, 27, 217-234. https://doi.org/10.1016/0021-8502(95)00562-5

Ehhalt, D., Prather, M., Dentener, F., Derwent, R., Dlugokencky, E. J., Holland, E., Isaksen, I., Katima, J., Kirchhoff, V., \& Matson, P. (2001). Atmospheric Chemistry and Greenhouse Gases. Richland, WA: Pacific Northwest National Lab.

Falkner, R. (2016). The Paris Agreement and the New Logic of International Climate Politics. International Affairs, 92, 1107-1125. https://doi.org/10.1111/1468-2346.12708

Fan, S. M., Horowitz, L. W., Levy, H., \& Moxim, W. J. (2004). Impact of Air Pollution on Wet Deposition of Mineral Dust Aerosols. Geophysical Research Letters, 31, 1-4. https://doi.org/10.1029/2003GL018501

Fuchs, N., \& Sutugin, A. (1971). High-Dispersed Aerosols. In G. M. Hidy and J. R. Brock 
(Eds.), Topics in Current Aerosol Research (p. 1). Oxford: Pergamon. https://doi.org/10.1016/B978-0-08-016674-2.50006-6

Gentry, J. W. (1972). Charging of Aerosol by Unipolar Diffusion of Ions. Journal of Aerosol Science, 3, 65-76. https://doi.org/10.1016/0021-8502(72)90142-5

Gillett, N. P., Stone, D. A., Stott, P. A., Nozawa, T., Karpechko, A. Y., Hegerl, G. C., Wehner, M. F., \& Jones, P. D. (2008). Attribution of Polar Warming to Human Influence. Nature Geoscience, 1, 750-754. https://doi.org/10.1038/ngeo338

Ginoux, P., Chin, M., Tegen, I., Prospero, J. M., Holben, B., Dubovik, O., \& Lin, S. J. (2001). Sources and Distributions of Dust Aerosols Simulated with the GOCART Model. Journal of Geophysical Research: Atmospheres, 106, 20255-20273. https://doi.org/10.1029/2000JD000053

Goldsmith, J. R. (1986). Effects on Human Health. In A. C. Stern (Ed.), Air Pollution (pp. 391-463). Cambridge, MA: Academic Press. https://doi.org/10.1016/B978-0-08-092605-6.50013-2

Goody, R. M., \& Yung, Y. L. (1995). Atmospheric Radiation: Theoretical Basis. Oxford: Oxford University Press.

Gu, Y. Y. (2019). Energy Planning for Sustainable Toronto High-Rise Development.

Gupta, D., \& Peters, M. H. (1985). A Brownian Dynamics Simulation of Aerosol Deposition onto Spherical Collectors. Journal of Colloid and Interface Science, 104, 375-389. https://doi.org/10.1016/0021-9797(85)90046-3

Gysel, M., Weingartner, E., \& Baltensperger, U. (2002). Hygroscopicity of Aerosol Particles at Low Temperatures. 2. Theoretical and Experimental Hygroscopic Properties of Laboratory Generated Aerosols. Environmental Science \& Technology, 36, 63-68. https://doi.org/10.1021/es010055g

Hallquist, M., Wenger, J. C., Baltensperger, U., Rudich, Y., Simpson, D., Claeys, M., Dommen, J., Donahue, N., George, C., \& Goldstein, A. (2009). The Formation, Properties and Impact of Secondary Organic Aerosol: Current and Emerging Issues. Atmos pheric Chemistry and Physics, 9, 5155-5236. https://doi.org/10.5194/acp-9-5155-2009

Hess, M., Koepke, P., \& Schult, I. (1998). Optical Properties of Aerosols and Clouds: The Soft-Ware Package OPAC. Bulletin of the American Meteorological Society, 79, 831-844. https://doi.org/10.1175/1520-0477(1998)079<0831:OPOAAC >2.0.CO;2

Highwood, E. J., \& Kinnersley, R. P. (2006). When Smoke Gets in Our Eyes: The Multiple Impacts of Atmospheric Black Carbon on Climate, Air Quality and Health. Environment International, 32, 560-566. https://doi.org/10.1016/j.envint.2005.12.003

Hiller, F. C., Mazumder, M. K., Wilson, J. D., \& Bone, R. C. (1980). Effect of Low and High Relative Humidity on Metered-Dose Bronchodilator Solution and Powder Aerosols. Journal of Pharmaceutical Sciences, 69, 334-337. https://doi.org/10.1002/jps.2600690321

Hodzic, A., Jimenez, J. L., Madronich, S., Canagaratna, M., DeCarlo, P. F., Kleinman, L., \& Fast, J. (2010). Modeling Organic Aerosols in a Megacity: Potential Contribution of Semi-Volatile and Intermediate Volatility Primary Organic Compounds to Secondary Organic Aerosol Formation. Atmospheric Chemistry \& Physics, 10, 5491-5514. https://doi.org/10.5194/acp-10-5491-2010

Houghton, E. (1996). Climate Change 1995: The Science of Climate Change: Contribution of Working Group I to the Second Assessment Report of the Intergovernmental Panel on Climate Change, 2. Cambridge: Cambridge University Press.

Howells, I. (1974). Drag Due to the Motion of a Newtonian Fluid through a Sparse Random Array of Small Fixed Rigid Objects. Journal of Fluid Mechanics, 64, 449-476. 


\section{https://doi.org/10.1017/S0022112074002503}

Jalaal, M., \& Ganji, D. (2011). On Unsteady Rolling Motion of Spheres in Inclined Tubes Filled with Incompressible Newtonian Fluids. Advanced Powder Technology, 22, 58-67. https://doi.org/10.1016/j.apt.2010.03.011

Jennings, S. (1988). The Mean Free Path in Air. Journal of Aerosol Science, 19, 159-166. https://doi.org/10.1016/0021-8502(88)90219-4

Karatzas, I., \& Shreve, S. E. (1998). Brownian Motion. In Brownian Motion and Stochastic Calculus (pp. 47-127). Berlin: Springer.

https://doi.org/10.1007/978-1-4612-0949-2 2

Kaufman, Y. J., \& Koren, I. (2006). Smoke and Pollution Aerosol Effect on Cloud Cover. Science, 313, 655-658. https://doi.org/10.1126/science.1126232

Kiehl, J., \& Briegleb, B. (1993). The Relative Roles of Sulfate Aerosols and Greenhouse Gases in Climate Forcing. Science, 260, 311-314.

https://doi.org/10.1126/science.260.5106.311

Levine, J. (2012). The Photochemistry of Atmospheres. Cambridge, MA: Academic Press.

Liao, H., \& Seinfeld, J. (1998). Radiative Forcing by Mineral Dust Aerosols: Sensitivity to Key Variables. Journal of Geophysical Research: Atmospheres, 103, 31637-31645. https://doi.org/10.1029/1998JD200036

Lighty, J. S., Veranth, J. M., \& Sarofim, A. F. (2000). Combustion Aerosols: Factors Governing Their Size and Composition and Implications to Human Health. Journal of the Air \& Waste Management Association, 50, 1565-1618.

https://doi.org/10.1080/10473289.2000.10464197

Lin, J.-T., Martin, R., Boersma, K., Sneep, M., Stammes, P., Spurr, R., Wang, P., Van Roozendael, M., Clémer, K., \& Irie, H. (2014). Retrieving Tropospheric Nitrogen Dioxide from the Ozone Monitoring Instrument: Effects of Aerosols, Surface Reflectance Anisotropy, and Vertical Profile of Nitrogen Dioxide. Atmospheric Chemistry and Physics, 14, 1441-1461. https://doi.org/10.5194/acp-14-1441-2014

Liousse, C., Penner, J., Chuang, C., Walton, J., Eddleman, H., \& Cachier, H. (1996). A Global Three-Dimensional Model Study of Carbonaceous Aerosols. Journal of Geophysical Research: Atmospheres, 101, 19411-19432. https://doi.org/10.1029/95JD03426

Liu, H., \& Rodríguez, G. (2005). Human Activities and Global Warming: A Cointegration Analysis. Environmental Modelling \& Software, 20, 761-773. https://doi.org/10.1016/j.envsoft.2004.03.017

Liu, X., Easter, R. C., Ghan, S. J., Zaveri, R., Rasch, P., Shi, X., Lamarque, J. F., Gettelman, A., Morrison, H., Vitt, F. and Conley, A. (2012). Toward a Minimal Representation of Aerosols in Climate Models: Description and Evaluation in the Community Atmosphere Model CAM5. Geoscientific Model Development, 5, 709-739.

https://doi.org/10.5194/gmd-5-709-2012

Miller, R. L., \& Tegen, I. (1998). Climate Response to Soil Dust Aerosols. Journal of Climate, $11,3247-3267$. https://doi.org/10.1175/1520-0442(1998)011<3247:CRTSDA>2.0.CO;2

Mitchell, J. F., Johns, T., Gregory, J. M., \& Tett, S. (1995). Climate Response to Increasing Levels of Greenhouse Gases and Sulphate Aerosols. Nature, 376, 501-504. https://doi.org/10.1038/376501a0

Montzka, S. A., Dlugokencky, E. J., \& Butler, J. H. (2011). Non- $\mathrm{CO}_{2}$ Greenhouse Gases and Climate Change. Nature, 476, 43-50. https://doi.org/10.1038/nature10322

Murthy, B. (1988). Aerosols and Radiation Budget in the Middle Atmosphere. Indian Journal of Radio and Space Physics, 17, 203-219. 
Myers, S. R., \& Yeakub Ali, M. (2008). Haemoglobin Adducts as Biomarkers of Exposure to Tobacco-Related Nitrosamines. Biomarkers, 13, 145-159. https://doi.org/10.1080/13547500701470561

Negele, J. W., \& Yazaki, K. (1981). Mean Free Path in a Nucleus. Physical Review Letters, 47, 71. https://doi.org/10.1103/PhysRevLett.47.71

Ng, N., Canagaratna, M., Zhang, Q., Jimenez, J., Tian, J., Ulbrich, I., Kroll, J., Docherty, K., Chhabra, P., \& Bahreini, R. (2010). Organic Aerosol Components Observed in Northern Hemispheric Datasets from Aerosol Mass Spectrometry. Atmospheric Chemistry and Physics, 10, 4625-4641. https://doi.org/10.5194/acp-10-4625-2010

Polyakov, I. V., Bekryaev, R. V., Alekseev, G. V., Bhatt, U. S., Colony, R. L., Johnson, M. A., Maskshtas, A. P., \& Walsh, D. (2003). Variability and Trends of Air Temperature and Pressure in the Maritime Arctic, 1875-2000. Journal of Climate, 16, 2067-2077. https://doi.org/10.1175/1520-0442(2003)016<2067:VATOAT>2.0.CO;2

Pöschl, U. (2005). Atmospheric Aerosols: Composition, Transformation, Climate and Health Effects. Angewandte Chemie International Edition, 44, 7520-7540. https://doi.org/10.1002/anie.200501122

Pruppacher, H., \& Klett, J. (2010). Microphysics of Clouds and Precipitation. In Atmospheric and Oceanographic Sciences Library (Vol. 18, pp. 433-446). Dordrecht: Springer. https://doi.org/10.1007/978-0-306-48100-0

Ramanathan, V., Crutzen, P., Kiehl, J., \& Rosenfeld, D. (2001). Aerosols, Climate, and the Hydrological Cycle. Science, 294, 2119-2124. https://doi.org/10.1126/science.1064034

Rogelj, J., Den Elzen, M., Höhne, N., Fransen, T., Fekete, H., Winkler, H., Schaeffer, R., Sha, F., Riahi, K., \& Meinshausen, M. (2016). Paris Agreement Climate Proposals Need A boost to Keep Warming Well below $2^{\circ}$ C. Nature, 534, 631-639. https://doi.org/10.1038/nature18307

Rood, M. J., Larson, T., Covert, D., \& Ahlquist, N. (1985). Measurement of Laboratory and Ambient Aerosols with Temperature and Humidity Controlled Nephelometry. Atmospheric Environment, 19, 1181-1190. https://doi.org/10.1016/0004-6981(85)90202-1

Rosenfeld, D., Lohmann, U., Raga, G. B., O’Dowd, C. D., Kulmala, M., Fuzzi, S., Reissell, A., \& Andreae, M. O. (2008). Flood or Drought: How Do Aerosols Affect Precipitation? Science, 321, 1309-1313. https://doi.org/10.1126/science.1160606

Santer, B. D., Taylor, K., Wigley, T., Johns, T., Jones, P., Karoly, D., Mitchell, J., Oort, A., Penner, J., \& Ramaswamy, V. (1996). A Search for Human Influences on the Thermal Structure of the Atmosphere. Nature, 382, 39-46. https://doi.org/10.1038/382039a0

Schleussner, C.-F., Rogelj, J., Schaeffer, M., Lissner, T., Licker, R., Fischer, E. M., Knutti, R., Levermann, A., Frieler, K., \& Hare, W. (2016). Science and Policy Characteristics of the Paris Agreement Temperature Goal. Nature Climate Change, 6, 827-835. https://doi.org/10.1038/nclimate3096

Schwartz, S. E., \& Andreae, M. O. (1996). Uncertainty in Climate Change Caused by Aerosols. Science, 272, 1121-1121. https://doi.org/10.1126/science.272.5265.1121

Sehmel, G. A. (1968). Aerosol Deposition from Turbulent Airstreams in Vertical Conduits. USA: Battelle-Northwest, Richland, Wash. Pacific Northwest Lab. https://doi.org/10.2172/4549565

Seinfeld, J. H., Pandis, S. N., \& Noone, K. (1998). Atmospheric Chemistry and Physics: From Air Pollution to Climate Change. Physics Today, 51, 88.

Sharma, A. R., Kharol, S. K., Badarinath, K., \& Singh, D. (2010). Impact of Agriculture Crop Residue Burning on Atmospheric Aerosol Loading-A Study over Punjab State, 
India. Annales Geophysicae, 28, 367-379. https://doi.org/10.5194/angeo-28-367-2010

Shove, E. (2010). Beyond the ABC: Climate Change Policy and Theories of Social Change. Environment and Planning A: Economy and Space, 42, 1273-1285. https://doi.org/10.1068/a42282

Signorell, R., Goldmann, M., Yoder, B. L., Bodi, A., Chasovskikh, E., Lang, L., \& Luckhaus, D. (2016). Nanofocusing, Shadowing, and Electron Mean Free Path in the Photoemission from Aerosol Droplets. Chemical Physics Letters, 658, 1-6. https://doi.org/10.1016/j.cplett.2016.05.046

Sokolik, I. N., \& Toon, O. B. (1996). Direct Radiative Forcing by Anthropogenic Airborne Mineral Aerosols. Nature, 381, 681-683. https://doi.org/10.1038/381681a0

Solomon, S., Portmann, R., Garcia, R., Randel, W., Wu, F., Nagatani, R., Gleason, J., Thomason, L., Poole, L., \& McCormick, M. (1998). Ozone Depletion at Mid-Latitudes: Coupling of Volcanic Aerosols and Temperature Variability to Anthropogenic Chlorine. Geophysical Research Letters, 25, 1871-1874. https://doi.org/10.1029/98GL01293

Spendlove, J. C., \& Fannin, K. F. (1983). Source, Significance, and Control of Indoor Microbial Aerosols: Human Health Aspects. Public Health Reports, 98, 229.

Stier, P., Seinfeld, J. H., Kinne, S., \& Boucher, O. (2007). Aerosol Absorption and Radiative Forcing. Atmospheric Chemistry and Physics, 7, 5237-5261. https://doi.org/10.5194/acp-7-5237-2007

Surratt, J. D., Murphy, S. M., Kroll, J. H., Ng, N. L., Hildebrandt, L., Sorooshian, A., Szmigielski, R., Vermeylen, R., Maenhaut, W., \& Claeys, M. (2006). Chemical Composition of Secondary Organic Aerosol Formed from the Photooxidation of Isoprene. The Journal of Physical Chemistry A, 110, 9665-9690. https://doi.org/10.1021/jp061734m

Tang, I. N., \& Munkelwitz, H. R. (1993). Composition and Temperature Dependence of the Deliquescence Properties of Hygroscopic Aerosols. Atmospheric Environment. Part A. General Topics, 27, 467-473. https://doi.org/10.1016/0960-1686(93)90204-C

Taylor, K. E., \& Penner, J. E. (1994). Response of the Climate System to Atmospheric Aerosols and Greenhouse Gases. Nature, 369, 734-737. https://doi.org/10.1038/369734a0

Torres, O., Bhartia, P., Herman, J., Ahmad, Z., \& Gleason, J. (1998). Derivation of Aerosol Properties from Satellite Measurements of Backscattered Ultraviolet Radiation: Theoretical Basis. Journal of Geophysical Research: Atmospheres, 103, 17099-17110. https://doi.org/10.1029/98JD00900

Turco, R. P., Whitten, R. C., Toon, O., Pollack, J. B., \& Hamill, P. (1980). OCS, Stratospheric Aerosols and Climate. Nature, 283, 283-285. https://doi.org/10.1038/283283a0

Turpin, B. J., \& Huntzicker, J. J. (1995). Identification of Secondary Organic Aerosol Episodes and Quantitation of Primary and Secondary Organic Aerosol Concentrations during SCAQS. Atmospheric Environment, 29, 3527-3544.

https://doi.org/10.1016/1352-2310(94)00276-Q

Uchino, O., \& Tabata, I. (1991). Mobile Lidar for Simultaneous Measurements of Ozone, Aerosols, and Temperature in the Stratosphere. Applied Optics, 30, 2005-2012. https://doi.org/10.1364/AO.30.002005

Watson, R. T., Rodhe, H., Oeschger, H., \& Siegenthaler, U. (1990). Greenhouse Gases and Aerosols. Climate Change: The IPCC Scientific Assessment, 1, 17.

Winker, D. M., Pelon, J. R., \& McCormick, M. P. (2003). CALIPSO Mission: Spaceborne Lidar for Observation of Aerosols and Clouds. Lidar Remote Sensing for Industry and Environment Monitoring III, 4893, 1-11. https://doi.org/10.1117/12.466539

Yamamoto, G., \& Tanaka, M. (1969). Determination of Aerosol Size Distribution from 
Spectral Attenuation Measurements. Applied Optics, 8, 447-453.

https://doi.org/10.1364/AO.8.000447

Zhang, K., Gao, H., Zhang, R., Zhu, Y. and Wang, Y. (2005). Sources and Movement Routes of Sand-Dust Aerosols and Their Impact Probabilities on China Seas in 20002002. Advances in Earth Science, 20, 627-636.

Zhang, R., Khalizov, A. F., Pagels, J., Zhang, D., Xue, H., \& McMurry, P. H. (2008). Variability in Morphology, Hygroscopicity, and Optical Properties of Soot Aerosols during Atmospheric Processing. Proceedings of the National Academy of Sciences of the United States of America, 105, 10291-10296. https://doi.org/10.1073/pnas.0804860105 